\title{
Ovarian ultrasound assessment in normal children, idiopathic precocious puberty, and during low dose pulsatile gonadotrophin releasing hormone treatment of hypogonadotrophic hypogonadism
}

\author{
R STANHOPE, J ADAMS, H S JACOBS, AND C G D BROOK \\ Endocrine Unit, Middlesex Hospital, London
}

SUMMARY Ultrasound assessment of ovarian volume, follicular size, and uterine growth was undertaken in 40 normal premenarcheal girls aged 6 months to 14 years. Ovarian follicles were detected from 6 months of age and increased in size and number, so that after the age of 8.5 years there was a progressive increase in the incidence of 'megalocystic' appearance. Eight girls with idiopathic precocious puberty had large megalocystic ovaries which regressed on treatment with gonadotrophin releasing hormone analogue. These findings contrasted with those seen in two prepubertal patients with hypogonadotrophic hypogonadism in whom the natural sequence of ovarian development was greatly accelerated by pulsatile administration of native gonadotrophin releasing hormone.

The initiation and maintenance of human sexual development requires the pulsatile release of gonadotrophins from the pituitary in response to pulsatile gonadotrophin releasing hormone. ${ }^{1}$ Treatment of hypogonadotrophic hypogonadism with pulsatile gonadotrophin releasing hormone can restore reproductive function in both males ${ }^{2}$ and females. ${ }^{3}$ The use of analogues that desensitise the pituitary response to endogenous gonadotrophin releasing hormone has been established as an effective treatment of idiopathic precocious puberty. ${ }^{4}$ Buserelin (6-D-Ser-(TBu)-GnRH-(1-9) ethylamide) is a superactive analogue that desensitises the pituitary by down regulation of the gonadotrope and thereby interferes with the secretion of gonadotrophins. ${ }^{5}$

Necropsy studies have shown that ovarian size increases gradually during childhood. ${ }^{6}$ Normal adolescent ovaries contain multiple follicular cysts ${ }^{7}$ whose development determines the rapid ovarian enlargement at puberty. ${ }^{8}$ Both ovarian and follicular size increase progressively from fetal life to puberty and there is histological evidence of a continued turnover of follicles throughout childhood. ${ }^{9}$ Ovaries containing multiple cysts have been shown by ultrasound in normal prepubertal girls ${ }^{10}$ and single or multiple follicular cysts have been reported in girls with precocious puberty. ${ }^{11}$

We have used ultrasound as a non-invasive method of assessing ovarian size and structure as well as uterine changes in normal children. We have compared the ovarian morphological changes of normal childhood with those seen during the suppression of idiopathic precocious puberty and during induction of puberty in patients with hypogonadotrophic hypogonadism.

\section{Patients and methods}

We studied 40 normal premenarcheal girls, eight with idiopathic precocious puberty, four of whom were treated with analogue, and two with delayed puberty treated by pulsatile administration of native gonadotrophin releasing hormone. All ultrasound scans were performed by JA using an Emisonic 4201 static scanner with a long focussed $3.5 \mathrm{mHz}$ transducer and more recently an Aloka sector scanner with $3.5 \mathrm{mHz}$ long focussed and $5.0 \mathrm{mHz}$ transducers. Ovarian volume was calculated by measuring length, width, and depth and by assuming the shape to be ellipsoid. ${ }^{12}$ Uterine size was estimated from measurements of maximum length and depth in sagittal section and expressed as cross sectional area.

Four of the patients with precocious puberty were treated with Buserelin (gonadotrophin releasing hormone analogue), given intranasally between 400 and $800 \mu \mathrm{g}$ daily in divided doses. Native gonado- 
trophin releasing hormone was administered subcutaneously in pulses using a miniature infusion pump: ${ }^{13}$ a dose of $15 \mu \mathrm{g}$ was administered at 90 minute intervals throughout 24 hours.

Informed parental consent was given for normal control patients.

\section{Results}

Ovarian volume gradually increased during childhood from a mean of $1 \mathrm{~cm}^{3}$ at 2 years of age to a mean of $2 \mathrm{~cm}^{3}$ at 12 years (Fig. 1). A maximum follicular diameter of $7 \mathrm{~mm}$ was normal in early childhood (Fig. 2). We define a 'megalocystic' ovary as one containing more than six follicles greater than $4 \mathrm{~mm}$ in diameter present in each ovary (Fig. 3). There was a progressive increase in the proportion of normal girls with megalocystic ovaries over the age of 8.5 years (Fig. 1). Uterine size was unchanged from 6 months to 10 years, mean cross sectional area was $2 \mathrm{~cm}^{2}$ (Fig. 4) and there was a rapid increase in uterine size after the age of 10 years associated with the onset of puberty.

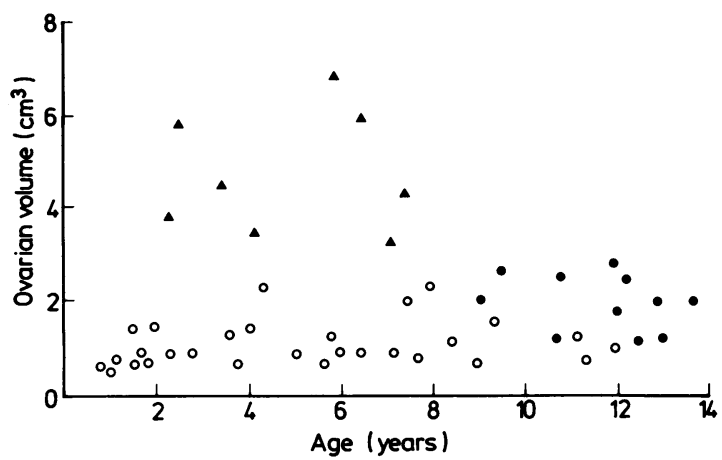

Fig. 1 Ovarian volume of $\mathbf{4 0}$ normal premenarcheal girls (circles) and eight girls with idiopathic precocious puberty (triangles).

Megalocystic ovaries are represented as solid symbols, those not megalocystic as open symbols.

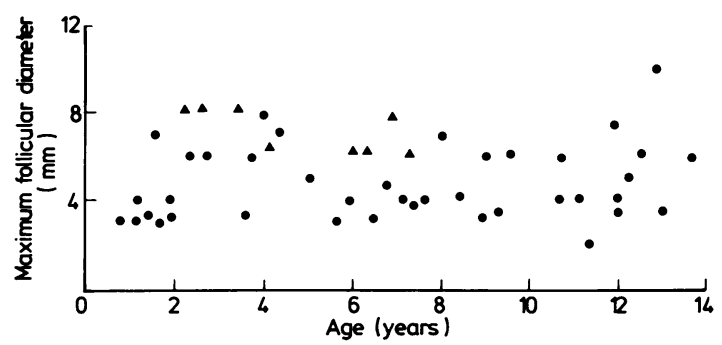

Fig. 2 Diameter of the largest ovarian follicle in either ovary of 40 normal premenarcheal girls (circles) and eight girls with idiopathic precocious puberty (triangles).

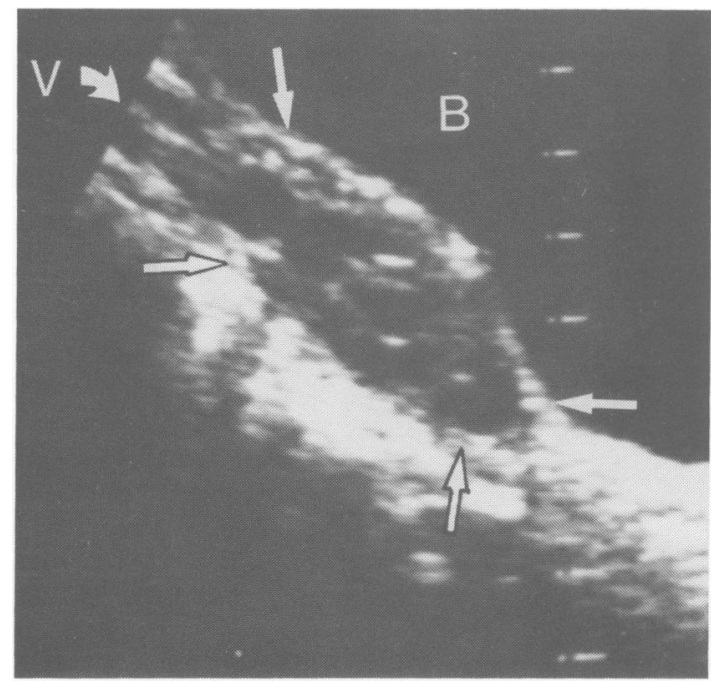

Fig. 3 Sagittal ultrasound image of a megalocystic ovary from a normal prepubertal $8 \cdot 8$ year old girl, seen through the bladder $(B)$ which is the dark area at the top of the image.

The white lines represent $1 \mathrm{~cm}$ markers. Arrows outline the margin of one ovary which contained eight 'cysts' greater than $4 \mathrm{~mm}$ in diameter. $\mathrm{V}$ indicates the ovarian vessels entering the superior pole of the ovary.

At presentation, all eight girls with idiopathic precocious puberty had large megalocystic ovaries, greater than $3 \mathrm{~cm}^{3}$ in volume (Fig. 1), which approached or fell within the normal adult range. Maximum follicular diameter was within the normal range for age (Fig. 2). All eight had uterine cross sectional areas greater than $4 \mathrm{~cm}^{2}$ (Fig. 4). Four of the eight patients were treated with intranasal gonadotrophin releasing hormone analogue which resulted in either arrest or regression of the clinical

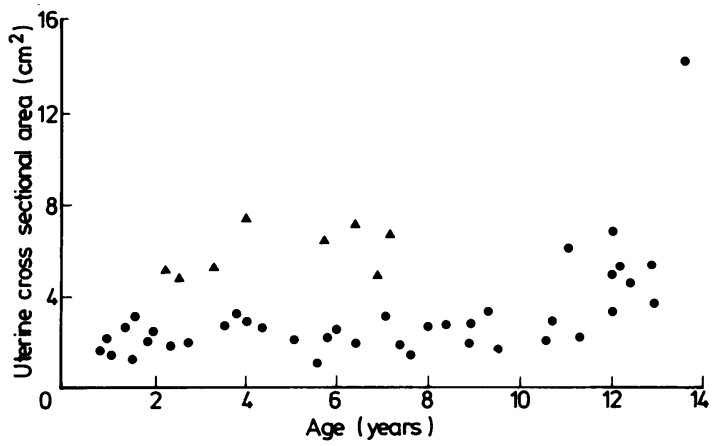

Fig. 4 Uterine cross sectional area of 40 normal premenarcheal girls (circles) and eight girls with idiopathic precocious puberty (triangles). 


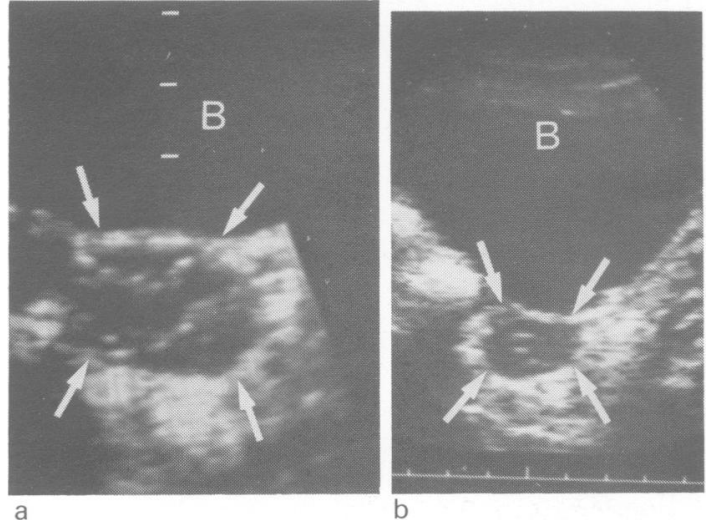

Fig. 5(a) Sagittal ultrasound image of one ovary (arrowed) of a 21/2 year old girl with idiopathic precocious puberty. The dark area at the top of the image is the bladder $(B)$.

Horizontal lines represent $1 \mathrm{~cm}$ markers. The ovary was large $(3.2 \times 2.2 \mathrm{~cm})$ and megalocystic. Breast development was Tanner stage III

(b) Sagittal ovarian ultrasound image from the same girl after one year of gonadotrophin releasing hormone analogue treatment.

The scale of $1 \mathrm{~cm}$ markers is along the bottom of the image. The ovary (arrowed) was reduced in size $(2.5 \times 1.7 \mathrm{~cm})$ and intra-ovarian cysts' were suppressed both in size and number. Breast development had regressed to Tanner stage II.

signs of their pubertal development. The change in pubertal status correlated with a decrease in ovarian size and regression of the megalocystic ovarian appearance (Fig. 5).

\section{Case reports}

Case 1. An 18 year old girl who presented with short stature and primary amenorrhoea, had been treated at the age of 17 years by transethmoidal resection of a craniopharyngioma. After the operation she had mild diabetes insipidus and adrenocorticotrophic and growth hormone deficiencies, for which she received hormone replacement treatment. Gonadotrophin responses to an intravenous diagnostic injection of gonadotrophin releasing hormone are shown in Fig. 6. Ovarian ultrasound showed small ovaries containing only a few small follicles, and a very small uterus. There was a gradual ovarian enlargement and increase in follicle numbers and size in response to pulsatile gonadotrophin releasing hormone treatment, so that by day 220 both ovaries were megalocystic.

Case 2. A 17 year old girl presented with no signs of puberty. Endocrine assessment showed no abnor-

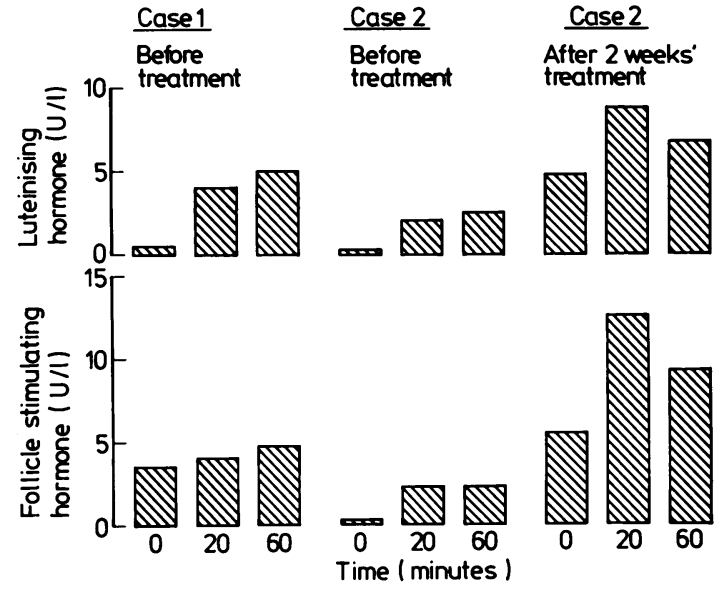

Fig. 6 Follicle stimulating hormone and luteinising hormone response, at 0,20 , and 60 minutes, to a diagnostic test of an intravenous injection of $100 \mu \mathrm{g}$ native gonadotrophin releasing hormone.

In case 2 the test was repeated after two weeks of pulsatile gonadotrophin releasing hormone treatment.

mality except in the gonadotrophin responses to a diagnostic test of $100 \mu \mathrm{g}$ intravenous gonadotrophin releasing hormone (Fig. 6). Ovarian ultrasound showed very small ovaries containing no follicles. Two weeks after beginning pulsatile treatment, there was a pronounced increase in the gonadotrophin response to a diagnostic test of intravenous gonadotrophin releasing hormone (Fig. 6). The pattern of growth of the ovary and uterus in response to treatment is shown in Fig. 7. After 8 weeks of treatment the ovaries became megalocystic. During a 10 day period of mechanical pump failure both ovaries and uterine size decreased,

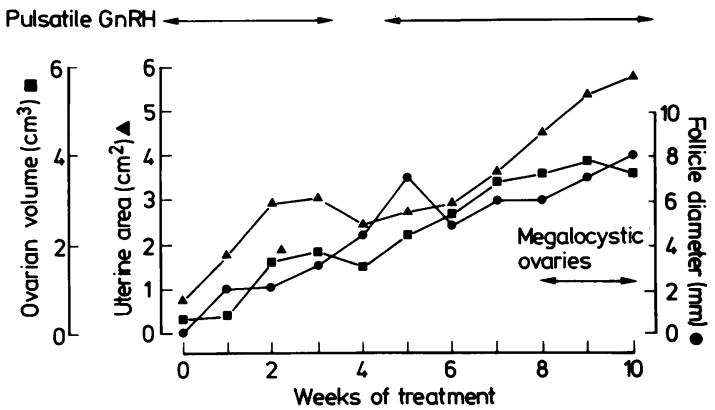

Fig. 7 Serial ultrasound data from a 17 year old girl with hypogonadotrophic hypogonadism (case 2) during treatment with pulsatile gonadotrophin releasing hormone.

A megalocystic ovarian appearance was established at 8 weeks of treatment. 
although follicular size continued to increase. She had developed stage II breast development ${ }^{14}$ after three months of treatment.

\section{Discussion}

Although ultrasound imaging provides a noninvasive method of assessing ovarian and uterine changes, there have been few gynaecological ultrasound studies in normal childhood. Difficulty has been experienced in ovarian ultrasonic definition in infants and young children, ${ }^{15}{ }^{16}$ even up to the age of 7 years. ${ }^{17}$ Our data on uterine and ovarian ultrasound assessment of normal girls is in agreement with more recent work. ${ }^{18}$ i9 In addition to measuring ovarian size we have been able to assess intra-ovarian morphology using ultrasound in normal girls as young as 6 months of age.

We have found that pelvic ultrasound assessment is helpful in the diagnosis and classification of precocious puberty. The presence of a large uterus with a cross sectional area greater than $4 \mathrm{~cm}^{2}$ confirms this diagnosis. In addition to the uterine changes, the ovaries in idiopathic precocious puberty are large, approach adult size, and are always megalocystic. An ovarian volume of greater than 3 $\mathrm{cm}^{3}$ is outside the normal range and confirms a diagnosis of idiopathic precocious puberty. Treatment with gonadotrophin releasing hormone analogue is associated with regression of the megalocystic ovarian appearance.

In our experience of inducing puberty in patients with hypogonadotrophic hypogonadism, changes occur in ovarian morphology and uterine size which closely resemble those seen in normal puberty. The megalocystic appearance is an ovarian response to pulsatile gonadotrophin secretion. We hypothesise that pulsatile secretion of gonadotrophin releasing hormone in low amplitude and long periodicity leads to the beginning of ovarian maturation early in childhood, before there are any clinical signs of puberty. A phase of megalocystic ovarian appearance occurs before the development of a dominant follicle. These changes can be reproduced in patients with hypogonadotrophic hypogonadism treated with pulsatile gonadotrophin releasing hormone by varying pulse frequency and amplitude. The megalocystic ovarian appearance is dependent on pulsatile gonadotrophin releasing hormone secretion and can be suppressed with analogue.

Ultrasound imaging has a key role in the diagnosis and management of disorders of sexual maturation, reducing the requirement for more complex biochemical measurements. The information afforded by this non-invasive technique offers a new way of establishing the relation of the neuroendocrine changes with the more familiar clinical markers of sexual maturation.

We thank Dr Patrick Magill, (Senior Medical Advisor, Hoescht UK) for supplies of native gonadotrophin releasing hormone and analogue (Buserelin).

\section{References}

1 Boyar RM, Finkelstein J, Roffwarg H, Kapen S, Weitzman E, Kellman L. Synchronisation of LH secretion with sleep during puberty. N Engl J Med 1972;287:582-6.

2 Hoffman AR, Crowley WF. Induction of puberty in men by long-term pulsatile administration of low dose gonadotrophin releasing hormone. $N$ Engl J Med 1982;307:1237-41.

${ }^{3}$ Crowley WF, McCarthur JW. Simulation of the normal menstrual cycle in Kallman's syndrome by pulsatile administration of luteinising hormone releasing hormone (LHRH). J Clin Endocrinol Metab 1980;51:173-5.

${ }^{4}$ Kauli R, Pertzelan A, Ben-Zeev Z, et al. Treatment of precocious puberty with LHRH analogue in combination with cyproterone acetate-further experience. Clin Endocrinol 1984;20:377-87.

5 Donaldson MDC, Stanhope R, Lee TJ, Price DA, Brook CGD, Savage DCL. Gonadotrophin responses to $\mathrm{GnRH}$ in precocious puberty treated with GnRH analogue. Clin Endocrinol 1984; 21:499-503.

6 Simbkins CS. Development of the human ovary from birth to sexual maturity. Am J Anat 1932;51:465-505.

7 Polhemus DW. Ovarian maturation and cyst formation in children. Pediatrics 1953;11:588-94.

${ }^{8}$ Krantz KE, Atkinson JP. Paediatric and adolescent gynaecology: gross anatomy. Ann N Y Acad Sci 1967;142:551-75.

9 Peters H, Byskov AG, Grinster J. The development of the ovary during childhood in health and disease. In: Coutts JRT, ed. Functional morphology of the human ovary. Lancaster: MTP Press, 1981:26-34.

${ }^{10}$ Cabrol S, Haseltine FP, Taylor KJJ, Viscomi G, Genel M. Ultrasound examination of pubertal girls and of patients with gonadal dysgenesis. J Adolesc Health Care 1981;1:185-92.

1 Haller JO, Friedman AP, Schaffer R, Lebensart DP. The normal and abnormal ovary in childhood and adolescence. Seminars in Ultrasound 1983;4:206-25.

12 Campbell S, Goessens L, Goswamy R, Whitehead M. Real-time ultrasonography for determination of ovarian morphology and volume. Lancet $1982 ; \mathbf{i}: 425-6$.

13 Sutherland IA, White S, Chambers GR, et al. A miniature infuser for the pulsatile administration of LHRH.J Biomed Eng 1984;6:129-33.

14 Tanner JM. Growth at adolescence. Oxford: Blackwell Publications, 1962.

15 Haller JO, Schneidner M, Kassner EG, et al. Ultrasonography in paediatric gynaecology and obstetrics. Am J Radiol 1977; 128:423-39.

16 Sample WF, Lippe BM, Gyepas MT. Gray scale ultrasonography of the normal female pelvis. Radiology 1977;125:477-83.

17 Ivarsson SA, Nilsson KO, Persson P-H. Ultrasonography of the pelvic organs in prepubertal and postpubertal girls. Arch Dis Child 1983;58:352-4.

18 Colle M, Calabet A, Sanciaume C, Battin J. Contribution of pelvic ultrasonography (PUS) to endocrine investigations in girls. Pediatr Res 1984;18:113.

19 Tassoni P, Salardi S, Orsini LF, et al. Ultrasound biometry of pediatric female internal genital structures. Pediatr Res 1984;18:114.

Correspondence to Dr C G D Brook, Middlesex Hospital, Mortimer Street, London W1N 8AA.

Received 28 August 1984 